\title{
Rare Forms of Diabetic Neuropathy in Clinical Practice: Case Report
}

\section{Larysa Tereshchenko $^{1 *}$ and Anatolii Sorokin ${ }^{2}$}

${ }^{1}$ Communal Enterprise "Dnepropetrovsk Regional Clinical Hospital Named After I.I.

Mechnikov" DRC, Dnipro, Ukraine

${ }^{2}$ Dnipro State Medical University, Dnipro, Ukraine

*Corresponding Author: Larysa Tereshchenko, 1Communal Enterprise

"Dnepropetrovsk Regional Clinical Hospital Named After I.I. Mechnikov" DRC,

Dnipro, Ukraine.
Received: December 10, 2021

Published: January 18, 2022

(C) All rights are reserved by Larysa

Tereshchenko and Anatolii Sorokin.

\begin{abstract}
The article is devoted to the problem of damage of the nervous system in diabetes mellitus. The prevalence of diabetic polyneuropathy is presented, the attention of practitioners is focused on the features of the course of its rare forms, in particular, thoracoabdominal neuropathy. A clinical case of thoracoabdominal neuropathy, features of its symptoms, course, diagnosis, differential diagnosis with diseases of internal organs and pathology of the gastrointestinal tract are presented. The supervision of such patients in a multidisciplinary hospital is proposed.
\end{abstract}

Keywords: Diabetic Neuropathy; Thoracoabdominal Neuropathy; Diabetes Mellitus; Abdominal Pain

\section{Introduction}

Diabetes mellitus (DM) is a group of metabolic diseases characterized by hyperglycemia and is the result of impaired insulin synthesis, the action of insulin, or both. Chronic hyperglycemia in diabetes is accompanied by damage, dysfunction or insufficiency of various organs and systems, in particular the nervous system, kidneys, heart and blood vessels, and eyes. The International Diabetes Federation (IDF) published an update in 2016 showing an increase in the number of patients with diabetes from 108 million to 422 million over the period 1980 - 2014. According to forecasts of experts from the World Health Organization and IDF, by 2030 the number of patients with diabetes is expected to increase worldwide to 552 million people. In Ukraine, there are currently 1 million 300 thousand patients with this pathology [1]. Most often, physicians with a somatic profile are faced with diabetic polyneuropathy (DP), one of the most common complications of diabetes [2]. The development of DP increases the mortality of patients with diabetes mainly due to the development of autonomic neuropathy, as well as complications of diabetes such as diabetic foot syndrome and its consequences [3]. DP is the cause of $50-75 \%$ of all nontraumatic amputations in diabetes. Distal symmetric sensorimotor polyneuropathy is observed in almost $30-50 \%$, peripheral painful polyneuropathy - in about $26 \%$ of cases and is accompanied by severe pain syndrome with a neuropathic nature of pain [4]. Damage of peripheral nerves in diabetes mellitus has its own characteristics in comparison with neuropathies of another genesis. Thus, in diabetes mellitus, in addition to multiple lesions of peripheral nerves, mononeuropathies are also noted, which have clinical features of the course and difficulties for differential diagnosis. One of the rare forms of focal (local) neuropathy is acute thoracoabdominal neuropathy. Below is a clinical case in order to draw the attention of doctors of all specialties to the problem of damage of the nervous system in diabetes, to remind about the features of the clinical course, diagnosis and differential diagnosis of rare forms of PD, in particular, acute thoracoabdominal neuropathy. 


\section{Clinical Case}

Patient M., female, was born in 1952, was admitted to communal enterprise "Dnepropetrovsk Regional Clinical Hospital named after I.I. Mechnikov" DRC" on April 13, 2018, with complaints of a sharp paroxysmal pain of an aching-burning character in the region of both hypochondria with alternating intensification without regard to physical activity and the position of the body in space. The patient noted an increase of pain at night. Before admission to the department, she was examined by the duty surgeons at the place of residence several times in an urgent manner. Diagnoses of acute cholecystitis, acute pancreatitis and other acute pathology of the chest and abdominal organs were excluded. At the same time, there was no therapeutic effect from the administration of spasmolytics and non-steroidal anti-inflammatory drugs, even in high doses.

From the anamnesis it is known that for 10 years he has been suffering from type 2 diabetes, has been using antihyperglycemic drugs, has been observed by a therapist for more than 20 years for arterial hypertension of stage II, 2nd degree, 3rd degree of risk. Analysis of medical records showed a stable dynamic of dyslipidemia over the past years with an increase in triglycerides up to 2.87 $\mathrm{mmol} / \mathrm{l}$, low-density lipoproteins - up to $3.89 \mathrm{mmol} / \mathrm{l}$, atherogenic coefficient - up to 3.5 .

On examination, the patient was noted to have grade 2 obesity (body mass index - $39.25 \mathrm{~kg} / \mathrm{m} 2$, waist circumference $-127 \mathrm{~cm}$ ); blood pressure in the background of using antihypertensive drugs - 150/100 mm Hg. Art. In the blood test, hyperglycemia 8.1 - 7.5 $\mathrm{mmol} / \mathrm{l}$ in the background of using combined antihyperglycemic therapy, an increase in the level of low-density lipoproteins up to $3.2 \mathrm{mmol} / \mathrm{l}$; no other changes in laboratory parameters were found.

In the neurological status, pain was noted during palpation of the intercostal spaces on both sides, more pronounced on the right in the area of ThVI - ThX dermatomes with symptoms of dysesthesia and hyperpathy. No painfulness during palpation of the spinous processes and paravertebral points in the mid- and lower thoracic spine was found.

During MRI (Figure 1) of the thoracic spine, the patient revealed scoliotic curvature of the spinal axis, osteochondrosis, spondyloarthrosis, posterior protrusions of ThV - ThVI, ThVI - ThVII discs up to $3 \mathrm{~mm}$ in size without narrowing of the vertebral foramen and signs of spinal cord compression, which did not determine the clinical picture diseases.

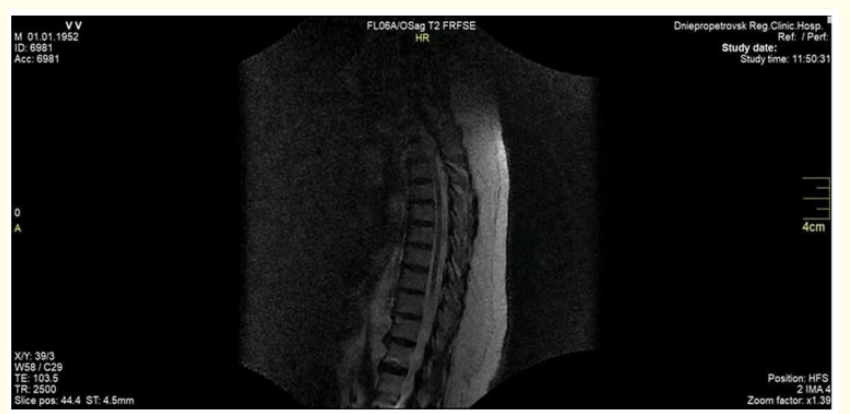

Figure 1: MRI 1.5 $\mathrm{T}$ of the thoracic spine.

According to the nature of the pain syndrome with a predominance of the neuropathic component, the lack of effect from the use of non-steroidal anti-inflammatory drugs and spasmolitics, a long history of diabetes, the absence of vertebrogenic changes and pathology of internal organs that explain this pain syndrome, the patient was diagnosed with thoracoabdominal neuropathy. The specified variant of damage to the nervous system is presented in the clinical classification of diabetic neuropathy $[4,5]$.

\section{Treatment}

According to the literature [6], thoracoabdominal neuropathy (radiculopathy) is a rare complication of diabetes, developing mainly in the elderly, the pathogenesis of which is based on the occlusion of the vasa nervorum. Considering the intense pain syndrome, localization of pain, sometimes such patients mistakenly undergo surgery (most often cholecystectomy). The neuropathic nature of the pain, as in the above case, in accordance with NICE neuropathic pain guideline [7] requires the admition of pregabalin at a dose of $300 \mathrm{mg} /$ day to the main therapy. As a result of treatment, regression of pain syndrome was noted according to the $\mathrm{Vi}$ sual Analogue Scale after 14 days of therapy in the hospital from 8 to 4 points, while sleep improved, and the severity of anxiety decreased.

\section{Conclusion}

Knowledge of the presence of rare forms of pathology of the peripheral nervous system in diabetes allows, on the one hand, to 
suspect the etiology of the disease, on the other hand, to prevent surgical intervention on the abdominal organs, as well as erroneous treatment of pathologies of the gastrointestinal tract (chronic cholecystitis, chronic pancreatitis, etc.). These neurological complications of diabetes mellitus explain the necessity of appropriate therapy for neuropathic pain.

\section{Conflict of Interest}

None.

\section{Bibliography}

1. WHO. Global report on diabetes (2016).

2. Kamchatnov PR., et al. "Damage to peripheral nervous system in diabetes mellitus". Medical Alphabet 4.33 (2018): 29-33.

3. Sadosky A., et al. "Burden of illness associated with painful diabetic peripheral neuropathy among adults seeking treatment in the US: results from a retrospective chart review and crosssectional survey". Diabetes, Metabolic Syndrome and Obesity 6 (2013): 79-92.

4. Thomas PK. "Diabetic peripheral neuropathies: their cost to patient and society and the value of knowledge of risk factors for development of interventions". European Neurology 41.1 (1999): 35-43.

5. Jamesson JL and De Groot LJ. "Endocrinology: Adult and Pediatric". $7^{\text {th }}$ ed. Elsevier, Amsterdam 1 (2016): 2704.

6. James W Russell., et al. "Diabetic neuropathies". Continuum (Minneap Minn) (5 Peripheral Nervous System Disorders) (2014): 1226-1240.

7. NICE. Neuropathic pain in adults: pharmacological management in non-specialist settings.

\section{Assets from publication with us}

- Prompt Acknowledgement after receiving the article

- Thorough Double blinded peer review

- Rapid Publication

- Issue of Publication Certificate

- High visibility of your Published work

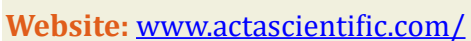
Submit Article: www.actascientific.com/submission.php Email us: editor@actascientific.com

Contact us: +919182824667 